\title{
Farklı Tür Agregalarla Üretilen Yüzeysel Kaplamaların Kayma Direnci Performanslarının İncelenmesi
}

\author{
Volkan Emre UZ ${ }^{* 1}$, İslam GÖKALP ${ }^{1}$ \\ ${ }^{1}$ Adana Bilim ve Teknoloji Üniversitesi, İnşaat Mühendisliği Bölümü, Adana
}

Geliş tarihi: 06.01.2017 Kabul tarihi: 14.03.2017

\section{$\ddot{\mathbf{O} z}$}

$\mathrm{Bu}$ çalışmada, doğal agregalardan ve cüruflardan oluşan farklı agrega tür ve tane boyutlarında ve gradasyonunda üretilen yüzeysel kaplamaların kayma direnci performansı araştırılmıştır. Bu amaç doğrultusunda, öncelikle her bir agreganın fiziksel, mekanik ve kimyasal özelikleri TS EN standartlarına göre belirlenmiştir. Sathi kaplama örnekleri; 2-19 mm aralığında değişen yedi farklı tane boyutunda hazırlanırken, harç tipi kaplama örnekleri ise üç farklı gradasyonda üretilmiştir. Üretilen yüzeysel kaplama numunelerinin, kayma dirençleri ve makro dokuları sırasıyla ASTM E 303 ve ASTM E 965 standartları göre belirlenmiştir. Yüzeysel kaplamaların kayma direnci karşılaştırıldığında, her boyut ve gradasyonda cüruflar ile üretilmiş olan numunelerin, doğal agrega ile üretilmiş olan numunelerden daha iyi performans gösterdiği gözlenmiştir.

Anahtar Kelimeler: Kayma direnci, Yüzeysel kaplamalar, Kaplama dokusu, Cüruf

\section{Evaluation of Skid Resistance Perfromance of Surface Coatings Manufactured with Different Aggregates}

\begin{abstract}
In this study, skid resistance performance of surface coatings, which were produced with different aggregate types including natural aggregates and slags and sizes and gradations were evaluated. Physical, mechanical and chemical properties of each aggregate were determined according to related EN standards. Chip seal samples were prepared with seven different particle size ranging from 2.00 to 19.00 $\mathrm{mm}$, whereas slurry seal samples were manufactured in three different gradations, which are specified in ASTM D 3910. To identify the skid resistances and macro-textures of each surface coating samples, ASTM E 303 and ASTM E 965 were followed. The results showed that skid resistance performance of the samples manufactured with slags higher that those produce with natural aggregates.
\end{abstract}

Keywords: Skid resistance, Surface coating, Pavement texture, Slag

\footnotetext{
*Sorumlu yazar (Corresponding author): Volkan Emre UZ,vemreuz@adanabtu.edu.tr
} 


\section{GíRIŞ}

Yük ve yolcu taşımacılığının büyük çoğunluğu karayolları ile yapılmakta ve trafik kazaları bu ulaştırma modunun ana sorununu oluşturmaktadır Karayolu kazaları binlerce ölüme ve yaralanmaya sebep olmakta ve çok büyük bir mali kayba yol açmaktadır. İnsan hatası en büyük kaza nedeni olarak ortaya çıksa da, yol kusurları da trafik kazalarına sebep olan önemli bir etkendir. Kayma tipi kazalar genellikle kaplama kayma direncinin düşük olmasına bağlı olarak ortaya çıkan ve yaygın görülen bir kaza tipidir. Kayma direnci, araç lastiği ile kaplama yüzeyi arasında oluşan sürtünme kuvvetinin bir göstergesidir ve trafik güvenliği bakımından önemli bir parametredir [1]. Kayma direncindeki düşüşün trafik kazalarında artışa sebep olması kayma direncinin önemini açıkça göstermektedir. Trafik ve iklim etkileri zamanla kaplamada kusma, sökülme, cilalanma vb. gibi bozulmalara neden olmakta ve bu bozucu etkiler altında kaplama kayma direncini zaman içerisinde düşüş göstermektedir [2]. Ayrıca, Kaplama türü, agregaların fiziksel ve mekanik özellikleri, bitüm miktarı ve özellikleri gibi faktörlerin kaplama uzun dönem kayma direnci performansı üzerinde etkisi olduğu bilinmektedir [3-6].

Kaplama kayma direncinin ölçülmesi karmaşık bir iştir. Bunun sebebi, kaplama özelliklerinden (doku, malzeme, sıcaklık), lastik özelliklerinden (diş tasarımı, kauçuk bileşeni, kayma hızı, sıcaklık) ve çevresel ve iklimsel koşullardan gelen ve ölçümleri etkileyen birçok faktörün olmasıdır [5-7]. Bu nedenle yıllar içerisinde en doğru kayma direnci değerini ölçmek için birçok cihaz ve metot geliştirilmiştir. Aynı kaplama yüzeyi için farklı ölçüm değerleri verebilen bu cihazlar, çalışma prensiplerine bağlı olarak üç ana grupta sınıflandırılabilir. Bunlar; yanal kuvvet katsayısı ölçen cihazlar, sabit veya düşük hızda ölçüm yapan cihazlar ve boyuna sürtünme katsayısı ölçen cihazlardır. $\mathrm{Bu}$ metotlarda farklı ölçüm hızları, lastik tipleri, tekerlek yükleri ve su film kalınlıkları kullanılmaktadır [8, 9]. Sabit veya düşük hızda ölçüm yapan cihazlar basit çalışma prensipleri, taşınabilir oluşları ve hem laboratuvar hem de saha ölçümlerinde kullanılabilir olmaları sebebiyle tercih edilmektedirler. Bu kapsamda, İngiliz Pandül Test Cihazı (BPT) tüm dünyada en iyi bilinen ve araştırma çalışmalarında da yaygın olarak kullanılan kayma direnci ölçüm cihazıdır. BPT, dinamik bir pandül olup, kauçuk kaydırıcı kenarlarının deney yüzeyi üzerindeki hareketi esnasındaki enerji kaybını ölçmek için kullanılan bir cihazdır. [5]. Bu test cihazı ülkemizde de yaygın olarak kullanılmakta ve ölçümlerde genellikle ASTM E303 [10] standardı takip edilmektedir. Ölçümleri düşük hızda gerçekleştirmesinden dolayı malzemenin mikro doku ölçümlerinde de yaygın olarak kullanılmaktadır. Kaplama kayma direnci ölçümünde kullanılan en basit ve ucuz aletlerden biridir. $\mathrm{Bu}$ çalışmada da bu yöntem, üretilen yüzeysel kaplama örneklerinin kayma direncinin tayin edilmesinde kullanılmıştır.

Kaplama yüzey dokusu üstyapının fonksiyonel kalitesi ve trafik güvenliği üzerinde oldukça etkili bir parametredir. Kaplama yüzey dokusu, periyodik ve tekrarlanan eğrilerin tepe noktaları arasındaki minimum mesafeye $(0-50 \mathrm{~m})$ bağlı olarak mikro, makro, mega doku ve düzgünsüzlük olmak üzere dört ana kategoriye ayrilır. [5,11,12]. Bir kaplamanın makro dokusu, akış-zaman ölçer ve kum yama gibi hacimsel tabanlı metotlar; lazer profil metre, lazer tarayıcı ve dairesel doku metre gibi lazer tabanlı metotlar ve X-ray, bilgisayarlı kesityazar, görüntü işleme ve fotogrametri gibi görüntüleme metotları kullanılarak ölçülebilir [13]. Bu çalışma kapsamında, hacimsel tabanlı metotlardan kum yama test metodu kullanılmış ve testlerde ASTM E 965-12 [14] standardı takip edilmiştir. $\mathrm{Bu}$ test metodunda, makro doku derinliğini boşlukları dolduran kumların oluşturduğu belli elek aralıklarında kalan malzemelerin hacmi belirler.

\section{2. ÖNCEKİ ÇALIŞMALAR}

Uluslararası Güvenli Yol Seyahati Derneği (ASIRT) tarafindan yayımlanan rapora göre, karayolu kazalarında her yıl yaklaşık 1,3 milyon kişi ölmekte (günlük 3.287 ölüm) ve 20-50 milyon insan yaralanmakta veya sakatlanmaktadır. Ek 
olarak, karayolu trafik kazaları ölüm nedenleri içerisinde 9. sıra ile önde gelen ölüm sebeplerindendir ve dünya çapındaki tüm ölümlerin \%2,2 sine karşllık gelmektedir [18] Önceki çalışmalar incelendiğinde trafik kazalarında üç temel faktörün varlı̆̆ına işaret etmektedir. Bunlar; sırasıyla insan faktörleri, yol ve yol çevresi faktörleri ve araç faktörleridir. Kaza oluşumuna neden olan faktörler içerisindeki payları ise sırasıyla yaklaşık olarak $\% 95, \% 28$ ve $\% 8$ 'dir [19-21].

Çok uzun yıllardan beri kaplama kayma direnci ile kaza oluşumu arasındaki ilişkiye odaklanmış araştırmalar yürütülmektedir [22]. Yapılan çalışmalar kaza oluşumunu azaltmak ve trafik güvenliğinin artırılması için en önemli yol yüzey özelliğinin kaplama kayma direnci olduğunu doğrulamaktadır. Kayma direnci, lastik yükü, basıncı, diş derinliği ve şekli, yol yüzey özellikleri, kaplama üzerinde su veya buzun bulunması ve sürüş hızı gibi faktörlere bağlıdır. Kayma direncini etkileyen faktörleri araç, yol, sürüş ve çevresel faktörler olarak sinıflandırmak mümkündür $[5,23]$.

Kaplama yüzeyinin düz bir yatay düzlemden sapan düzensizlikleri kaplama yüzey dokusu olarak bilinir. Yüzey dokusu, genişlik ve dalga boyu olarak tanımlanan boyutlarına bağlı olarak, araçkaplama etkileşimini birçok açıdan etkiler. Bunlar; kaymaya karşı direnç, lastik-kaplama gürültüsü, su sıçratma ve püskürtme, yuvarlanma direnci ve lastik aşınmasıdır [24-26] Makro doku, frekansı $0,5 \mathrm{~mm}$ ile $50 \mathrm{~mm}$ ve şiddeti $0,1 \mathrm{~mm}$ ile $20 \mathrm{~mm}$ arasında değișen dokudur ve agrega boyutları ve aralarındaki boşluklar tarafindan kontrol edilir. Mega doku, $50 \mathrm{~mm}$ ile $5000 \mathrm{~mm}$ frekansa ve $0,1 \mathrm{~mm}$ ile $50 \mathrm{~mm}$ arasında değişen şiddete sahip sapmalardır ve yol yüzeyindeki büyük ölçekli bozulmaların ve kusurların oluşturduğu dokudur. Düzgünsüzlük ise $500 \mathrm{~mm}$ 'den büyük dalga boylarını belirtmek için kullanılır [5,11,26,27]. Kaplama yüzey dokusu, agrega mineralojisi, agrega boyutu ve gradasyonu, yüzey boşlukları, yol kaplaması inşa teknikleri ve yüzey aşınmasına bağlıdır [15,24,28]. Servis ömrü boyunca bir kaplamanın kayma direnci ağılıklı olarak yüzey dokusu (makro ve mikro doku) tarafindan etkilenir. Kaplama mikro ve makro dokusunda azalmaya yol açan birçok sebep bulunmaktadır. Bunlar: cilalanma, soyulma, sökülme, gömülme, kusma, terleme, tekerlek izi gibi bozulmalar ve yüzey kirliliği ve sıcaklık gibi çevresel faktörlerdir $[29,30]$. Ayrıca, yağışlı hava ve kaplama kayma direnci kaybı arasında güçlü bir ilişki olduğu yapılan çalışmalar ile ortaya konmuştur [2,31].

Dünya nüfusu her geçen gün büyümektedir. Ulaşım yatırımları ve mevcut altyapının genişleme ve bakım ihtiyacı da doğal olarak artmaktadır. $\mathrm{Bu}$ nedenle, kaliteli agrega ihtiyacı sürekli artmakta ve doğal kaynaklara olan talep de büyümeye devam etmekte ancak doğal agrega kaynakları giderek azalmaktadır. Bu durum, araştırmacıları teknik, çevresel ve ekonomik fizibilite yönünden agrega gibi kullanılabilecek alternatif malzemelere yönlendirmiştir [32,33]. Tüm dünyada, metalürji sanayi büyük miktarlarda endüstriyel yan ürün üretmektedir [34]. Çelik cürufu, çelik üretim süreci sonucunda ortaya çıkan bir yan üründür ve üretimde kullanılan çeşitli katkı maddelerinin oksidasyonu sonucu ortaya çıkan oksit ve silikatlardan oluşan karmaşık kimyasal bir yapıya sahiptir. Cüruflar doğal agregalarla karşıllaştırıldığında sertlik ve aşınma direnci gibi fiziko-mekanik özellikler bakımından daha üstün özelliklere sahip olduğu araştırmalarla ortaya çıkarılmıştır.

Ülkemiz, Türkiye yıllık 50 milyon ton üretim kapasitesi ile dünyadaki en büyük çelik üreticilerinden biridir. Türkiye Çelik Üreticileri Derneği tarafindan yayımlanan rapora göre 2015 yılı üretimi yaklaşık 35 milyon tondur. Toplam çelik üretiminin yaklaşı \% 72 'sini (25 milyon ton) elektrik ark firınları (EAF) ile yapılan üretim teşkil etmektedir. Toplam çelik üretiminin \%10-15'inin cüruf olarak oluştuğunu dikkate aldığımızda her yıl yaklaşık 4,5 milyon ton cüruf ortaya çıktığ 1 öngörülebilir [32,33].

Yüzeysel kaplamalar mevcut kaplamaların bakımını yaparak özelliklerini iyileştirmek, koruyucu bir tabaka gibi mevcut üstyapının ömrünü uzatmak veya düşük hacimli yollarda direkt olarak bir kaplama tabakası olarak kullanılmaktadır. Uygulama yöntemlerine bağlı olarak yüzey kaplamalarını sathi kaplamalar ve 
harç tipi kaplamalar olarak iki kategoriye ayırmak mümkündür. Sathi kaplamalar yüzeye önce bağlayıcının püskürtülmesi ve ardından mıcırın serilmesi ve sıkıştırılması ile imal edilirken, harç tipi kaplamalar belirli miktarda agreganın ve bitümün karıştırılması ve serilmesi ile üretilmektedir. Genel olarak, sathi veya harç tipi kaplamalar, diğer kaplama koruma ve iyileştirme yöntemleriyle karşılaştırıldığında efektif, ekonomik ve kolay uygulanabilir olmaları nedeniyle genel olarak tercih edilmektedir $[15,16]$. Yüzeysel kaplamaların performansı yapım şartları, malzeme özellikleri ve miktarları, trafik, hava ve çevre koşulları gibi bir takım faktörlere bağlıdır [35].

\section{MATERYAL VE METOT}

\subsection{Materyal}

Yüzeysel kaplamalar, agrega ve bitümlü bağlayıcılardan meydana gelmektedir. Çalışmanın bu bölümünde, kullanılan agregalar ve bitümlü bağlayıcılar anlatılacaktır.

\subsubsection{Agregalar}

$\mathrm{Bu}$ çalışma kapsamında doğal kayaçlar ve endüstriyel yan ürünlerden oluşan toplam on çeşit agrega kullanılmıştır. Agregalar, Türkiye'nin Akdeniz ve Güneydoğu Anadolu Bölgelerinden olmak üzere 9 farklı il ve/veya ilçe sınırları içerisinde hizmet veren agrega ocakları, demir çelik işletmeleri veya cüruf depolama sahalarından temin edilmiştir. Geniş spektrumda sonuçlar elde etmek amaciyla birer kaynaktan dere malzemesi (DR) ve Ferrokrom (FER) cürufu, üçer kaynaktan kireçtaşı (KT) ve EAF cürufu ve iki kaynaktan bazalt (BZ) agregası kullanılmıştır. Belirtildiği üzere, doğal agregalar özel agrega/taş ocaklarından, cüruflar ise işletmelerin cüruf depolama sahalarından veya atık toplama sahalarından tedarik edilmiştir.

Agregalar, betonarme yapılarda, yol üstyapısında ve diğer toprak işlerinde kullanılan temel malzemelerdendir. Yol üstyapısında kullanılacak olan agregalarda bir takım özellikler aranmaktadır. Aranılan bu fiziksel ve mekanik özelliklerin tayin edilebilmesi için agregalara bir dizi test uygulanmaktadır. Bunlar; aşınma direnci tayini (\%) için Micro-Deval testi (A), parçalanma direnci tayini (\%) için Los-Angeles testi (B), isıl bozulma direnci tayini (\%) için $\mathrm{MgSO}_{4}$ solüsyonu çevrimi (C), cilalanma direnci tayini (PSV) için hızlandırılmış parlatma testi (D), kuru birim hacim ağırlık $\left(\mathrm{g} / \mathrm{cm}^{3}\right)(\mathrm{E})$ ve su emme yüzdesi tayini $(\%)$ (F) testileridir. Ayrıca, çalışmada kullanılan agregaların malzeme özelliklerini tam olarak ortaya koyabilmek için kimyasal bileşenlerini tanımlamak önemlidir. Bu nedenle, X-ray floresan (XRF) kimyasal element analizi yapılmıştır. Tüm testler ilgili TS EN standartları takip edilerek yapılmıştır. İki tekrar olarak yapılan testlerden elde edilen ortalama sonuçlar Çizelge 1'de verilmiştir.

Çizelge 1. Agregaların fiziksel, mekanik özellikleri ve kimyasal bileşenleri

\begin{tabular}{|c|c|c|c|c|c|c|c|c|c|c|c|c|}
\hline \multirow{2}{*}{$\begin{array}{c}\text { Numune } \\
\text { Kodu }\end{array}$} & \multicolumn{4}{|c|}{ Fiziksel ve Mekanik Özellikler } & \multicolumn{5}{c|}{ Kimyasal Birleşenler (mg/kg) } \\
\cline { 2 - 15 } & $\mathrm{A}$ & $\mathrm{B}$ & $\mathrm{C}$ & $\mathrm{D}$ & $\mathrm{E}$ & $\mathrm{F}$ & $\mathrm{CaO}$ & $\mathrm{CO}_{2}$ & $\mathrm{Fe}_{2} \mathrm{O}_{3}$ & $\mathrm{SiO}_{2}$ & $\mathrm{Al}_{2} \mathrm{O}_{3}$ & $\mathrm{MgO}$ \\
\hline KT-1 & 10,6 & 24,4 & 2,4 & 41,2 & 2,7 & 0,4 & 47,6 & 47,0 & 0,4 & 1,4 & 0,6 & 0,5 \\
\hline KT-2 & 21,3 & 16,2 & 3,0 & 43,2 & 2,7 & 0,2 & 48,9 & 47,2 & 0,0 & 0,9 & 0,2 & 0,3 \\
\hline KT-3 & 11,7 & 24,4 & 8,1 & 41,6 & 2,7 & 0,3 & 47,5 & 46,5 & 0,3 & 1,2 & 0,6 & 0,8 \\
\hline BZ-1 & 10,4 & 12,0 & 6,9 & 61,0 & 2,6 & 2,0 & 8,5 & 5,6 & 7,4 & 49,9 & 18,1 & 3,3 \\
\hline BZ-2 & 9,4 & 25,9 & 9,4 & 52,4 & 2,7 & 1,4 & 7,5 & 5,5 & 6,0 & 56,8 & 16,0 & 1,6 \\
\hline DR & 11,3 & 17,5 & 6,2 & 57,9 & 2,7 & 0,9 & 31,0 & 28,9 & 4,7 & 22,7 & 5,6 & 4,0 \\
\hline EAF-1 & 9,5 & 22,9 & 2,3 & 76,1 & 3,4 & 1,8 & 25,6 & 17,5 & 28,7 & 10,6 & 5,8 & 1,7 \\
\hline EAF-2 & 8,8 & 25,3 & 8,3 & 59,0 & 3,4 & 2,5 & 21,8 & 37,9 & 15,4 & 10,3 & 4,5 & 2,5 \\
\hline EAF-3 & 12,3 & 29,7 & 3,7 & 54,1 & 3,3 & 2,9 & 22,6 & 18,1 & 26,0 & 12,1 & 6,1 & 4,5 \\
\hline FER & 7,6 & 16,5 & 6,1 & 61,7 & 2,9 & 1,1 & 4,5 & 22,0 & 1,4 & 23,8 & 14,9 & 28,3 \\
\hline
\end{tabular}




\subsubsection{Bitümlü Bağlayıcılar}

Bu çalışmada, sathi kaplama numuneleri hazırlamak için Karayolları Genel Müdürlüğü (KGM) tarafindan yayınlanan ve Türkiye'nin değişik bölgelerinde sathi kaplama yapımında kullanılacak bitüm seçim haritasında öngörülen 70/100 penetrasyonlu bitüm kullanılmıştır. Bitümün fiziksel özelliklerini tanımlamak için penetrasyon, yumuşama noktası, kütle değişimi, parlama noktası ve çözünürlük testleri uygulanmıştır. Testlerde takip edilen standartlar ve elde edilen sonuçlar Çizelge 2'de verilmiştir.

Çizelge 2. Bitüm özellikleri

\begin{tabular}{|l|c|c|}
\hline Özelikler & Standart & Sonuç \\
\hline Penetrasyon $(\times 0,1 \mathrm{~mm})$ & EN 1426 & 76 \\
\hline Yumuşama Noktas1 $\left({ }^{\circ} \mathrm{C}\right)$ & EN 1427 & 48 \\
\hline Kütle Değişimi $(\%)$ & EN 12607-1 & 0,8 \\
\hline Parlama Noktas1 $\left({ }^{\circ} \mathrm{C}\right)$ & EN ISO 2592 & 230 \\
\hline Çözünürlük $(\%)$ & EN 12592 & 99 \\
\hline
\end{tabular}

Harç tipi kaplamalar, yüzeysel kaplama türlerinden ikincisidir. $\mathrm{Bu}$ tür kaplamaların üretilmesinde, genellikle, emülsiyon kullanılır. $\mathrm{Bu}$ çalışma kapsamında üretilen her bir harç tipi kaplamada bağlayıcı olarak CRS-2 ile kodlanan, çabuk kesilen katyonik emülsiyon kullanılmıştır. Emülsiyonun reçetesi Çizelge 3'de verilmiştir.

Çizelge 3. Emülsiyon reçetesi

\begin{tabular}{|c|c|c|}
\hline Malzemeler & Tür & $\begin{array}{c}\text { Miktar } \\
(\mathrm{kg})\end{array}$ \\
\hline Bitüm & $50 / 70$ & 710 \\
\hline \multirow{5}{*}{ Su } & $\mathrm{Su}$ & 290 \\
\hline \multirow{5}{*}{ Çözelti } & $\begin{array}{c}\text { Emülgator } \\
\text { (Redicote Em 22/44) }\end{array}$ & 1 \\
\cline { 2 - 3 } & $\begin{array}{c}\text { Emülgator } \\
\text { (RC-406) }\end{array}$ & 2 \\
\cline { 2 - 3 } & $\mathrm{HCl}$ & 2 \\
\cline { 2 - 3 } & $\mathrm{CaCl}$ & 1 \\
\cline { 2 - 3 } & $\mathrm{Kat} 1$ & 2 \\
\hline
\end{tabular}

\subsection{Metot}

Çalışma kapsamında, yüzeysel kaplama uygulaması olarak sathi kaplama ve harç tipi kaplama olmak üzere iki tür kaplama üretilmiştir.
$\mathrm{Bu}$ bölümde, öncelikle numunelerin üretilmesinde takip edilen tasarım prosedürü, sonrasında kayma direnci ve makro doku ölçümlerinde kullanılan yöntemler detaylı bir şekilde anlatılmıştır.

\subsubsection{Sathi Kaplama Tasarımı}

Çalışma kapsamında, her bir agrega türü için dane boyutları 2-19 mm arasında değișen yedi farklı sathi kaplama numunesi üretilmiştir.

Makro doku derinliği genel olarak agrega büyüklüğüne, şekline ve agreganın yüzeye yerleşimine bağlıdır. Kırılma şekli ve kırım işleminde kullanılan kırıcı tipinden dolayı agregalar içerisinde farklı oranlarda bulunabilecek yassı tanelerin sonuçlara etki etmemesi için ASTM D 4791 ve EN-933-3'e göre uzun ve yassı olan parçalar agregalardan ayrıştırılmış ve yüzeysel kaplama numunelerin hazırlanması için sadece kübik agregalar kullanılmıştır. 6,3 mm'ye eşit ya da küçük agregalarda yassı ve uzun parçacıkların ayrılmasına gerek görülmemiştir [36].

Serbest malzeme ve tozun agregadan ayrıştırılması, agrega ve bitümün arasındaki adezyon için çok önemlidir. Bundan dolayı, bütün agregalar yıkanmış ve $100 \pm 5^{\circ} \mathrm{C}$ 'de fanlı etüvde kurutulmuştur. Agrega serme miktarı, ortalama en küçük boyut (ALD) teorisine dayalıdır. Bu teori, agreganın en düz tarafında konumlandırılmış iken, beklenen sathi kaplama kalınlığını temsil etmektedir [37]. Yeni Zelanda sathi kaplama tasarım kitapçığında belirtilen formüle göre, agrega serpme miktarı (ASM) Eşitlik 1'de verilen formüle göre hesaplanmıştır.

$\mathrm{ASM}=950 / \mathrm{ALD}$

Örnekleri hazırlamada $180 \mathrm{~mm}$ iç, $200 \mathrm{~mm}$ dış çapı olan, ve bağlayıcıyı plakanın içinde tutmak için $3 \mathrm{~mm}$ derinliği olan galvaniz metal plaka kullanılmıştır. Agregaların her biri farklı birim ağırlığa sahip olduğundan, ASM $\mathrm{ml} / \mathrm{m}^{3}$ cinsinden hesaplanmıştır. Uygulanan agrega serpme oranları ve hesaplanan ALD değerleri Çizelge 4'te verilmiştir. 
Çizelge 4. Agrega serim miktarı

\begin{tabular}{|c|c|c|}
\hline $\begin{array}{c}\text { Agrega } \\
\text { Boyutları } \\
(\mathrm{mm})\end{array}$ & $\begin{array}{c}\text { ALD } \\
(\mathrm{mm})\end{array}$ & $\begin{array}{c}\text { ASM } \\
\left(\mathrm{ml} / \mathrm{m}^{2}\right)\end{array}$ \\
\hline $19,0-16,0$ & 17,5 & 510 \\
\hline $16,0-12,5$ & 14,3 & 420 \\
\hline $12,5-10,0$ & 11,3 & 330 \\
\hline $10,0-8,0$ & 9,0 & 260 \\
\hline $8,0-6,3$ & 7,2 & 210 \\
\hline $6,3-4,0$ & 5,15 & 150 \\
\hline $4,75-2,0$ & 3,4 & 100 \\
\hline
\end{tabular}

Yüzeysel kaplamadaki bitüm oranı İngiltere tasarım metoduna göre belirlenmiştir. Roberts ve Nicholls (2008) [38] tarafından bağlayıcı oranını hesaplamak için dikkate alınacak faktörler, trafik, mevcut yüzey, iklim koşulları ve agrega veya mıcır türleridir. $\mathrm{Bu}$ parametrelerin ağırlık faktörleri Çizelge 5'te verilmiştir. Seçilen parametrelerden ağırlık faktörleri belirlenir. Bağlayıcı uygulama oranı Eşitlik 2 ile hesaplanabilir.

$$
R=0,0625+F \times 0,023+(0,0375+F \times 0,0011) \times A L D
$$

Buradaki eşitlikte; R, bitümün miktarını $\left(\mathrm{kg} / \mathrm{m}^{2}\right) \mathrm{F}$ ise toplam ağırlık faktörünü belirtmektedir.

Çalışmada trafik için orta, mevcut yüzey için az bitümlü, iklim için 1 lık ve son olarak agrega şekli için kübik seçilmiş ve bütün ağırlık faktörlerinin (f) toplamı sıfır olarak hesaplanmıştır. Her agrega gradasyonu için, plaka boyutuna göre bitüm miktarı belirlenmiş, Çizelge 6'da verilmiştir.

\subsubsection{Harç Tipi Kaplama Tasarımı}

Harç tipi kaplamalar, asfalt emülsiyonunun, gradasyonlu ince agreganın, mineral fillerin, suyun ve diğer katkı maddelerinin karışımı ile imal edilir. Harç tipi kaplama numunelerinin dizaynında, ASTM D 3910 [17] standardı kullanılmıştır. Bu standartta 3 tip harç tipi kaplama karışımlarda kullanılacak agrega gradasyonuna göre tanımlanmıştır. Çizelge 7'de her üç tip harç tipi kaplama için kullanılan agrega gradasyonları ve oranları verilmiştir.
Çizelge 5. Bitüm miktarının hesabında kullanılan değişkenler ve ağrılık faktörleri

\begin{tabular}{|c|c|c|}
\hline \multicolumn{3}{|c|}{ TRAFIK } \\
\hline Trafik Hacmi & Araçlar (L/D) & $\mathrm{f}$ \\
\hline Çok az & $0-50$ & 3 \\
\hline $\mathrm{Az}$ & $50-250$ & 1 \\
\hline Orta & $250-500$ & 0 \\
\hline Orta-Yüksek & $500-1000$ & -1 \\
\hline \multicolumn{3}{|c|}{ YÜZEY } \\
\hline \multicolumn{2}{|c|}{ Mevcut Yüzey } & $\mathrm{f}$ \\
\hline \multicolumn{2}{|c|}{ Bakımı yapılmamış } & 6 \\
\hline \multicolumn{2}{|c|}{ Çok az bitümlü } & 4 \\
\hline \multicolumn{2}{|c|}{ Az bitümlü } & 0 \\
\hline \multicolumn{2}{|c|}{ Otalama bitümlü } & -1 \\
\hline \multicolumn{2}{|c|}{ Çok bitümlü } & -3 \\
\hline \multicolumn{3}{|c|}{ İKLİM } \\
\hline \multicolumn{2}{|c|}{ İklimsel koşullar } & $\mathrm{f}$ \\
\hline \multicolumn{2}{|c|}{ Islak ve Soğuk } & 2 \\
\hline \multicolumn{2}{|c|}{ Islak ve Sicak } & 1 \\
\hline \multicolumn{2}{|c|}{ Ilık } & 0 \\
\hline \multicolumn{2}{|c|}{ Yarı kurak } & -1 \\
\hline \multicolumn{2}{|c|}{ Kurak } & -2 \\
\hline \multicolumn{3}{|c|}{ AGREGA } \\
\hline \multicolumn{2}{|c|}{ Agrega Türü } & $\mathrm{f}$ \\
\hline \multicolumn{2}{|c|}{ Yuvarlak } & 2 \\
\hline \multicolumn{2}{|c|}{ Kübik } & 0 \\
\hline \multicolumn{2}{|c|}{ Yass1 } & -2 \\
\hline \multicolumn{2}{|c|}{ Kaplamalı } & -2 \\
\hline
\end{tabular}

Çizelge 6. Bitüm miktarının hesabında kullanılan değişkenler ve ağrılık faktörleri

\begin{tabular}{|c|c|}
\hline $\begin{array}{c}\text { Agrega boyutlar } \\
(\mathrm{mm})\end{array}$ & $\begin{array}{c}\mathrm{R} \\
\left(\mathrm{g} / \mathrm{m}^{2}\right)\end{array}$ \\
\hline $19,0-16,0$ & 30,0 \\
\hline $16,0-12,5$ & 27,5 \\
\hline $12,5-10,0$ & 25,0 \\
\hline $10,0-8,0$ & 23,0 \\
\hline $8,0-6,3$ & 21,0 \\
\hline $6,3-4,0$ & 20,0 \\
\hline $4,75-2,0$ & 19,0 \\
\hline
\end{tabular}


Çizelge 7. Harç tipi kaplama agrega gradasyonları

\begin{tabular}{|c|c|c|c|}
\hline \multirow{2}{*}{$\begin{array}{l}\text { Elek } \\
\text { Çap1 } \\
(\mathrm{mm})\end{array}$} & \multicolumn{3}{|c|}{ \% Geçen } \\
\cline { 2 - 4 } & Tip-1 & Tip-2 & Tip-3 \\
\hline 9,50 & - & 100 & 100 \\
\hline 4,75 & 100 & 95 & 80 \\
\hline 2,36 & 95 & 77,5 & 57,5 \\
\hline 1,18 & 77,5 & 57,5 & 39 \\
\hline 0,60 & 50 & 40 & 26,5 \\
\hline 0,30 & 33,5 & 24 & 18,5 \\
\hline 0,15 & 22,5 & 15,5 & 10,5 \\
\hline 0,075 & 15 & 10 & 10 \\
\hline
\end{tabular}

Harç tipi kaplamalar için kullanılması önerilen agrega miktarları Tip-1, Tip-2 ve Tip-3 için sirasiyla $4 \pm 1,8 \pm 1,10 \pm 1,5 \mathrm{~kg} / \mathrm{m}^{2}$, dir ve $0,025 \mathrm{~m}^{2}$ plaka için Tip-1, Tip-2 ve Tip-3 gradasyonlarda toplamda 100,200 ve $250 \mathrm{~g}$ doğal agrega kullanılmıştır. EAF ve FER cüruflarının birim ağırlı̆ğ doğal agregalardan yüksek olduğu için, cüruflu harç tipi kaplamalar da ağırlıkça bir düzeltme yapılması gerekmiştir. Harç tipi kaplamaların üretiminde kullanılan cüruf miktarları (LS-1) kireç taşı referans alınarak belirlenmiş̧ir.

Çizelge 8. Harç-tipi kaplamada cüruf miktarları

\begin{tabular}{|c|c|c|c|}
\hline $\begin{array}{c}\text { Numune } \\
\text { Kodu }\end{array}$ & $\begin{array}{c}\text { Tip-1 } \\
(\mathrm{g})\end{array}$ & $\begin{array}{c}\text { Tip-2 } \\
(\mathrm{g})\end{array}$ & $\begin{array}{c}\text { Tip-3 } \\
\text { (g) }\end{array}$ \\
\hline EAF-1 & 130 & 260 & 320 \\
\hline EAF-2 & 130 & 260 & 320 \\
\hline EAF-3 & 130 & 250 & 310 \\
\hline FER & 110 & 220 & 280 \\
\hline
\end{tabular}

Emülsiyon uygulama oranı, kuru agrega ağıllı yüzdesi ile harç tipi kaplama türüne bağlı olarak ASTM D 3910 standardında tanımlanmaktadır. Buna bağlı olarak, her bir harç tipi kaplama türü için tavsiye edilen miktarlar kuru agrega miktarı yüzdesi oranı olarak belirlenmiştir. $\mathrm{Bu}$ oranlar; Tip-1 için \% 10-16 Tip-2 için \%7,5-13,5 ve Tip-3 için \%6,5-12 olarak standartta tanımlanmıştır. Çalışma kapsamında tüm harç tipi kaplama örnekleri için agrega karışımına eklenen emülsiyon miktarı üst limit değerinden uygulanmıştır.

\subsubsection{Kaplama Numunelerinin Hazırlanması}

Laboratuvar koşullarında sathi kaplama üretiminde şu adımlar takip edilmiştir: Hesaplanan agrega miktarı hacimsel olarak ölçülerek $100 \pm 5^{\circ} \mathrm{C}$ 'de etüvde 1sit1lır. Agrega gradasyonuna göre bitüm miktar1 tartılır ve $145 \pm 5^{\circ} \mathrm{C}^{\prime} \mathrm{de}$ 1sitılır. Bitüm $100 \pm 5^{\circ} \mathrm{C}$ 'de 1 sitılmış plaka üzerine spatula yardımıyla yayılır ve agrega bitümlü plaka üzerine düzgün olarak serilir ve kauçuk kaplı silindir ile üç pas olacak şekilde iki yönde silindirlenir ve numuneler 24 saat oda sıcaklığında kür edilir.

Harç tipi kaplama numuneleri üretebilmek için ise şu adımlar takip edilmiştir: Herhangi bir yapışma problemini önlemek için plaka astarlanır. Agrega ve bitüm miktarı tartılır. Emülsiyon $60^{\circ} \mathrm{C}$ 'de 1 saat su havuzunda şartlandırılır. Agregalar bir sprey yardımıyla ıslatılır ve bitüm ile karıştırılır. Hazırlanan karışım astarlanmış plaka üzerine yayılır ve her iki yönde üç pas olacak şekilde silindirlenir ve 24 saat oda sicaklığında küre birakilır.

\subsubsection{Kaplama Kayma Direnci Ölçümü}

$\mathrm{Bu}$ çalışmada, numunelerin kayma direnci ölçümünde ASTM E 303 standardı kullanılmış ve testler şu işlem adımları takip edilerek yapılmışıır:

1) Test alanının ve/veya numune yüzeyinin hazırlanması: Numune serbest parçalardan arındırılır ve BPT numunenin üzerine yerleştirir ve su terazisi ve tesviye vidası yardımıla cihaz dengelenir.

2) Sıfırlama ayarı: $\mathrm{Bu}$ adım gerçekte bir çeşit kalibrasyon adımıdır. Pandül mekanizması yükseltilir ve kilitlenir. Pandül serbest bırakılır, işaretçinin gösterdiği değer sıfir değil ise, sürtünme halkası rulman mili hafifçe çevrilir ve tekrar kilitlenir.

3) Kaydırıcı yükseklik ayarı: Pabucun numune üzerinde temas etmesi gerek özel uzunluk yükseklik ayar vidası ve özel cetvel yardımıyla ayarlanır. Eğer temas yolu, test numunesinin üzerinde 124 ve $127 \mathrm{~mm}$ aralığında değilse cihazın önündeki tesviye vidasını yükseltilip düşürerek ayarlamak gerekmektedir.

4) Testin uygulanmasi: Son adım testin uygulanmasıdır. Teste başlamadan önce, numune 
yüzeyi ve kaydırıcı pabuç 1slatılır. Bırakma düğmesine basılır ve pandül kolunun serbestçe kendi yayınca salınmasına izin verir. Dönüş yolunda kol kaydırıcı yüzeyine temas etmeden yakalanır. Test, her defasında numune yüzeyi ıslatarak beş kez tekrarlanır ve sonuçlar kayıt edilir.

\subsubsection{Kaplama Makro Doku Ölçümü}

$\mathrm{Bu}$ çalışmada, kaplama yüzeylerinin makro dokularını belirlemede kum yama testi ASTM E 965 standardı takip edilerek kullanılmıştır.

$\mathrm{Bu}$ test metodunda, makro doku derinliğini boşlukları dolduran kumların oluşturduğu malzemelerin hacmi belirler. Testin, laboratuvarda hazırlanan numuneler üzerinde uygulanma sırası şu şekildedir: İlk olarak temiz yüzey üzerine önceden belirlenen miktarda kum dökülür ve kum yayıcı tokmak ile dairesel hareketlerle dağıtılır. $\mathrm{Bu}$ dağıtma hareketleri dairenin çapı sabitleninceye ve kum tanecikleri boşlukları tamamen doldurana kadar devam eder ve yüzeyde en yüksek noktalar görünene kadar yayıma devam edilir. Bu süreçten sonra dairenin çapı eşit aralıklı olacak şekilde dört yönden ölçülür. En sonunda dört okumanın ortalaması belirlenir ve ortalama doku derinliği aşağıdaki eşitlik (3) kullanılarak hesaplanır.

$\mathrm{MTD}=4 \mathrm{~V} / \pi \mathrm{D}^{2}$

Burada;

MTD, Ortalama doku derinliğini, V, kum hacmi ve $\mathrm{D}$, ortalama kum çapını belirtmektedir.

\section{BULGULAR VE TARTIŞMA}

\subsection{Kaplama Kayma Direnci}

Çalışma kapsamında, 7 farklı agrega çapında sathi kaplama, 3 farklı gradasyonda harç tipi kaplama numuneleri, doğal agrega ve cüruf içeren 10 faklı agrega türünden imal edilmiştir. Her bir agrega türü için üretilen tüm yüzeysel kaplamalara için yapılan kayma direnci ölçüm sonuçları Şekil 1-3'te verilmiştir.

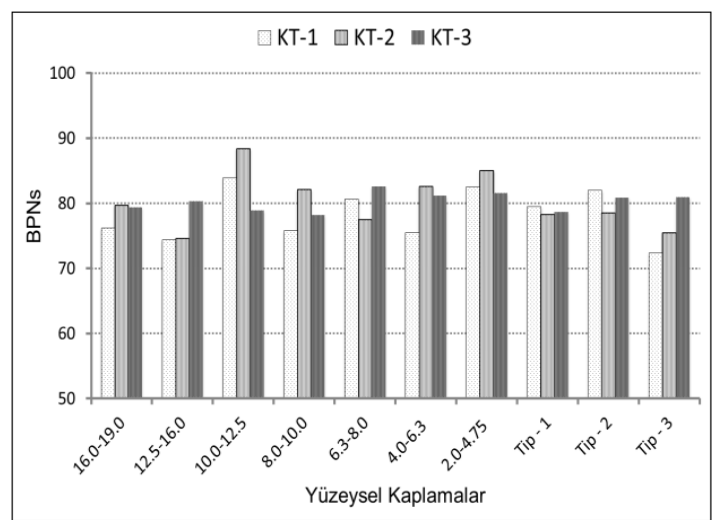

Şekil 1. Kireçtaşı agregaları ile üretilmiş yüzeysel kaplamaların kayma dirençleri

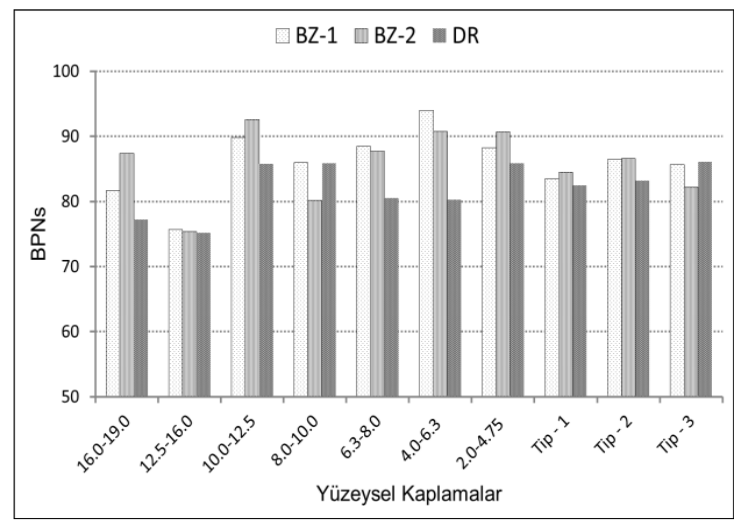

Şekil 2. Bazalt ve dere malzemesi agregaları ile üretilmiş yüzeysel kaplamaların kayma dirençleri

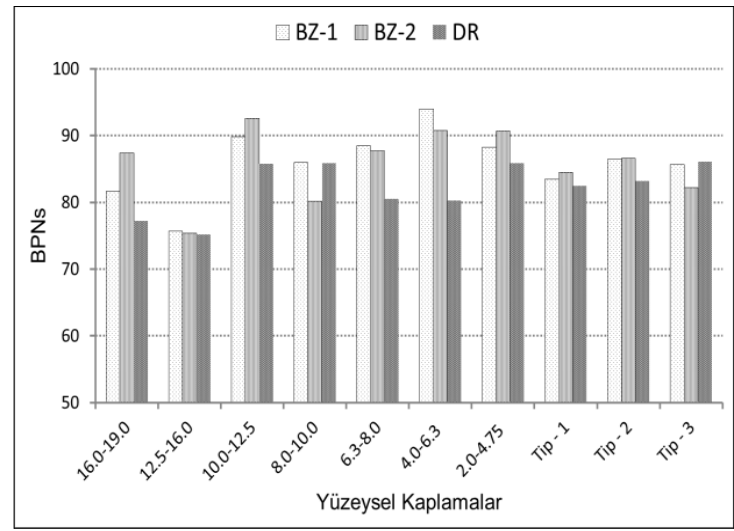

Şekil 3. Cüruf agregaları ile üretilmiş yüzeysel kaplamaların kayma dirençleri 


\subsection{Kaplama Makro-Dokusu}

Çalışma kapsamında, 7 farklı agrega çapında sathi kaplama, 3 farklı gradasyonda harç tipi kaplama numuneleri, doğal agrega ve cüruf içeren 10 faklı agrega türünden imal edilen her bir yüzeysel kaplama için yapılan makro doku ölçüm sonuçları verilmiştir. Makro doku, agrega taneleri arasındaki boşlukların oluşturduğu ve büyük oranda agrega boyutu, tane ve kırılma şekli tarafindan kontrol edilen dokudur. Metot kısmında tanımlandığ 1 gibi tane şeklinin makro dokuya olan etkisini ortadan kaldırmak için tüm malzemeler yassılık eleklerinden elenerek yassı tanelerinden arındırılmıştır.

Çizelge 9'da verilen sonuçlardan da görüleceği üzere kullanılan agrega boyutu arttıkça kaplamaların makro doku derinlikleri de beklendiği gibi artmaktadır. Cüruf yüzeyleri daha pürüzlü olduğundan genellikle aynı boyutta cüruf ile üretilen kaplamaların ortalama doku derinliği doğal agregalarla üretilen kaplamalardan daha fazladır. Bunun nedeni kum yayma işleminin cüruflu yüzeylerde biraz daha zor olmasıdır. 2,00-4,75 mm agrega kullanılarak üretilen sathi kaplamaların ortalama doku derinlikleri 2,5 ila 3,5 $\mathrm{mm}$ arasında değişirken 16,0-19,0 mm agregalar ile üretilen kaplamaların doku derinlikleri 7,7 ila $10,5 \quad \mathrm{~mm}$ arasında değişmektedir.

\section{SONUÇ ve ÖNERİLER}

Bu çalışmada, yüzey kaplamalarının kayma direnci performansının agrega türüne, tane boyutlarına ve gradasyonlarına göre nasıl değiştiği laboratuvar ortamında değerlendirilmiştir. Buna göre üç değişik kökende (kireçtaşı, bazalt, dere malzemesi) altı doğal agrega ve iki farklı kaynaktan (elektrik ark firın cürufu ve ferrokrom cürufu) dört cüruf yüzey kaplama üretimi için kullanılmıştır. Her bir agreganın fiziksel, kimyasal ve mekanik özellikleri ilgili testler ve standartlara göre belirlenmiştir. Laboratuvarda standart plakalar üzerinde üretilen her bir yüzeysel kaplama numunesinin doku derinliğini ölçmek için literatürde iyi bilinen hacimsel test yöntemi (kum yama) kullanılmıştır. Her numunenin kayma direncini belirlemek için dünyada en yaygın olarak kullanılan İngiliz Pandül Cihazı kullanılmıştır.

Çizelge 9. Makro doku ölçüm sonuçları

\begin{tabular}{|c|c|c|c|c|c|c|c|c|c|c|}
\hline $\begin{array}{c}\text { Agrega } \\
\text { Boyutlar1 } \\
(\mathrm{mm})\end{array}$ & KT-1 & KT-2 & KT-3 & BZ-1 & BZ-2 & DR & EAF-1 & EAF-2 & EAF-3 & FER \\
\hline $4 y, 75-2,00$ & 2,69 & 2,61 & 2,52 & 2,87 & 3,34 & 2,39 & 2,56 & 3,30 & 3,44 & 3,17 \\
\hline $6,30-4,00$ & 2,93 & 2,88 & 2,60 & 3,36 & 3,58 & 3,11 & 3,44 & 4,05 & 3,32 & 3,40 \\
\hline $8,00-6,30$ & 4,14 & 3,51 & 4,11 & 4,33 & 4,09 & 3,85 & 4,72 & 4,90 & 4,90 & 4,54 \\
\hline $10,00-8,00$ & 4,64 & 4,36 & 4,70 & 5,02 & 4,51 & 4,76 & 5,24 & 5,82 & 5,04 & 5,22 \\
\hline $12,50-10,00$ & 5,11 & 5,11 & 5,22 & 5,86 & 6,05 & 5,66 & 6,24 & 6,97 & 6,85 & 6,42 \\
\hline $16,00-12,50$ & 7,92 & 6,65 & 7,44 & 7,40 & 7,94 & 6,86 & 8,84 & 8,67 & 8,90 & 8,09 \\
\hline $19,00-16,00$ & 8,81 & 7,70 & 8,53 & 9,05 & 9,53 & 8,55 & 10,11 & 9,40 & 10,56 & 10,01 \\
\hline Tip-1 & 0,65 & 0,68 & 0,59 & 0,83 & 0,71 & 0,65 & 0,59 & 0,87 & 0,59 & 0,67 \\
\hline Tip-2 & 0,86 & 0,70 & 0,64 & 0,98 & 0,82 & 0,77 & 0,87 & 1,02 & 0,74 & 0,97 \\
\hline Tip-3 & 1,06 & 0,92 & 0,76 & 1,09 & 0,97 & 1,03 & 1,51 & 2,18 & 1,45 & 1,59 \\
\hline
\end{tabular}


Bu çalışma ile elde edilen sonuçlar ve öneriler şu şekilde sıralanabilir.

1. Agregalar fiziksel ve mekanik özellikleri açısından karşılaştırıldığında, cürufların doğal agregalara göre üstün ve zayıf özellikleri vardır. Örneğin, cürufların su emme miktarları ve kuru birim hacim ağırlıkları doğal agregalara oranla daha yüksektir. Kullanım amacına da bağlı olmakla beraber bu özellikleri bir dezavantaj olarak düşünülebilir. Öte yandan doğal agrega ile karşılaştırıldığında cürufların aşınma, parçalanma, ayrılma, cilalanma dirençleri doğal agregalara nazaran çok daha üstündür.

2. Cüruflarla üretilmiş yüzey kaplamalarının kayma direncini karşılaştıracak olursak, hemen hemen tüm doğal agregalara göre daha iyi performans göstermiştir. Yüzeysel kaplama uygulamalarında cüruf kullanımı ile yüksek kayma dirençli ve uzun ömürlü kaplama yüzeyleri elde etmenin mümkün olacağı ve bakım onarım maliyetlerinde azalma ve kayma tipine bağlı trafik kazaları sonucu oluşan can ve mal kaybını azaltacağı öngörülebilir.

3. Bu çalışmada, bir yüzeysel kaplamanın kayma direncinin mikro doku değişiminden önemli ölçüde etkilendiği ancak kayma direnci ile makro doku değişimi arasında güçlü bir ilişkinin bulunmadığı söylenebilir.

4. Cürufların geri dönüştürülerek yüzeysel kaplamalarda kullanılması ile çevresel, agrega temin ve işleme maliyetinin azaltılması ile de ekonomik yararlar sağlanabilir. Ayrıca cürufların agrega olarak kullanılması ile cüruf bertaraf ve depolama maliyetleri düşürülebilir ve doğal agrega tüketimi azaltılabilir. Türkiye'nin jeolojik yapısına da bağlı olarak özellikle ülkemizin güney bölgesinde istenilen kalitede yol kaplama agrega temini her zaman mümkün olamamakta veya tedariki taşıma maliyeti açısından pahalı olabilmektedir. Özellikle bu bölgelerde çokça ortaya çıkan cüruf yaşanan bölgesel sıkıntıların çözümünde de etkili olabilir.

\section{KAYNAKLAR}

1. Rezaei, A., Masad, E., Chowdhury, A., 2011. Development of a Model for Asphalt Pavement Skid Resistance Based on Aggregate Characteristics and Gradation, Journal of Transportation Engineering, vol. 137, pp. 863873.

2. Mayora, J. M. P., Piña, R. J., 2009. An Assessment of the Skid Resistance Effect on Traffic Safety Under Wet-Pavement Conditions, Accident Analysis \& Prevention, vol. 41, pp. 881-886.

3. Do, M.T., Cerezo V., 2015. Road Surface Texture and Skid Resistance, Surface Topography: Metrology and Properties, vol. 3, p. 16,

4. Asi, I. M., Qasrawi, H. Y., Shalabi, F. I., 2007. Use of Steel Slag Aggregate in Asphalt Concrete Mixes, Canadian Journal of Civil Engineering, vol. 34, pp. 902-911,

5. Kogbara, R. B., Masad, E. A. E., Kassem, Scarpas, A. T., Anupam, K., 2016. A State-ofthe-art Review of Parameters Influencing Measurement and Modeling of Skid Resistance of Asphalt Pavements, Construction and Building Materials, vol. 114, pp. 602-617,

6. Fwa, T., Choo, Y., Liu, Y. 2003. Effect of Aggregate Spacing on Skid Resistance of Asphalt Pavement, Journal of Transportation Engineering, vol. 129, pp. 420-426,

7. Artamendi, I., Phillips, P., Allen, B., Woodward, D. 2013. Development of UK Propietary Asphalt Surfacing Skid Resistance and Texture, in Airfield and Highway Pavement Sustainable and Efficient Pavements, pp. 865-874.

8. Sandberg, U., 1987. Road Traffic Noise - The Influence of the Road Surface and its Characterization, Applied Aqustics, vol. 21, pp. 97-118,

9. Andriejauskasa, T., Vorobjovasa, V., Mielonasb, V., 2014. Evaluation of Skid Resistance Characteristics and Measurement Methods, Proceedings of the International Conference on Environmental Engineering. ICEE, Vol. 9, p. 1. 
10. ASTM, ASTM E 303 Standard Test Method for Measuring Surface Frictional Properties using the British Pendulum Tester, ed, 2012.

11. Martino, M. M., Weissmann, J., 2008. Evaluation of Seal Coat Performance Using Macro-texture Measurements, Texas Department of Transportation, Technical Report (9/05 - 8/07) FHWA/TX-08/0-5310-3

12. Saykin, V. V., Zhang, Y., Cao, Y., Wang, M. L., McDaniel, J. G., 2012. Pavement Macrotexture Monitoring Through Sound Generated by a Tire-Pavement Interaction, Journal of Engineering Mechanics, vol. 139, pp. 264-271.

13. Sengoz, B., Topal, A., Tanyel, S., 2012. Comparison of Pavement Surface Texture Determination by Sand Patch Test and 3D Laser Scanning, Periodica Polytechnica. Civil Engineering, vol. 56, p. 73.

14. ASTM, ASTM E 965-12, Standard Test Method for Measuring Pavement Macrotexture Depth using a Volumetric Technique, ed, 2012.

15. Adams, J. M., Richard Kim, Y., 2014. Mean Profile Depth Analysis of Field and Laboratory Traffic-Loaded Chip Seal Surface Treatments, International Journal of Pavement Engineering, vol. 15 , pp. 645-656.

16. Praticò, F. G., Vaiana, R., Iuele, T., 2015. Macrotexture Modeling and Experimental Validation for Pavement Surface Treatments, Construction and Building Materials, vol. 95, pp. 658-666.

17. ASTM, ASTM D3910 - 11 Standard Practices for Design, Testing, and Construction of Slurry Seal, ed, 2012, p. 8.

18. ASIRT. (2016, 13.04.2016). Annual Global Road Crash Statistics.

19. Carrillo, M. C., Flores Anaya, M. R., Lopez, V., 2000. Risk Factors in Highway Traffic Accidents: A Case Control Study, Accident Analysis \& Prevention, vol. 32, pp. 703-709.

20. Andreescu, M.-P., Frost, D. B. 1998. Weather and Traffic Accidents in Montreal, Canada, Climate Research, vol. 9, pp. 225-230.

21. Hayakawa, H., Fischbeck P. S., Fischhoff, B. 2000. Traffic Accident Statistics and Risk Perceptions in Japan and the United States, Accident Analysis \& Prevention, vol. 32, pp. 827-835.
22. Lindenmann, H., 2006. New Findings Regarding the Significance of Pavement Skid Resistance for Road Safety on Swiss Freeways, Journal of safety research, vol. 37, pp. 395-400.

23. Andriejauskasa, T., Vorobjovasa, V., Mielonasb, V., 2014, Evaluation of Skid Resistance Characteristics and Measurement Methods, in $9^{\text {th }}$ International Conference on Environmental Engineering, Vilnius, Lithuania, p. 8 .

24. Ahammed, M., Tighe, S., 2009. Early-Life, Long-Term, and Seasonal Variations in Skid Resistance in Flexible and Rigid Pavements, Transportation Research Record: Journal of the Transportation Research Board, pp. 112-120.

25. Huang, C., 2010. Texture Characteristics of Unpolished and Polished Aggregate Surfaces, Tribology International, vol. 43, pp. 188-196.

26. Mahboob Kanafi, M., Kuosmanen, A., Pellinen, T. K., Tuononen, A. J., 2015. Macroand Micro-Texture Evolution of Road Pavements and Correlation with Friction, International Journal of Pavement Engineering, vol. 16, pp. 168-179.

27. Bitelli, G., Simone, A., Girardi, F., Lantieri, C. 2012. Laser Scanning on Road Pavements: A New Approach for Characterizing Surface Texture, Sensors, vol. 12, p. 9110.

28. Loprencipe G., Cantisani, G., 2013. Unified Analysis of Road Pavement Profiles for Evaluation of Surface Characteristics, Modern Applied Science, vol. 7, p. 1.

29. Kumar, P., 2014. Laboratory Base Pavement Surface Analysis Based on Materials, International Journal of Emerging Trends in Science and Technology, 1(07).

30. Bazlamit, S. M., Reza, F., 2005. Changes in Asphalt Pavement Friction Components and Adjustment of Skid Number for Temperature, Journal of Transportation Engineering, vol. 131, pp. 470-476.

31. Fwa, T., Ong, G.P., 2008. Wet-pavement Hydroplaning Risk and Skid Resistance: Analysis, Journal of Transportation Engineering, vol. 134, pp. 182-190.

32. Gökalp, İ., Uz, V.E., Saltan, M., 2016. Testing the Abrasion Resistance of Aggregates Including By-products by using Micro Deval Apparatus with Different Standard Test 
Methods, Construction and Building Materials, vol. 123, pp. 1-7.

33. Uz, V.E., Gökalp, İ., Epsileli, S.E., Tepe, M., 2014. Karayollari Teknik Şartnamesinde (KTŞ) Yer Alan Pürüzlendirme Uygulaması ve $\mathrm{Bu}$ Uygulamada Endüstriyel Atıkların Kullanılabilirliği, Karayolları 3 Ulusal Kongresi, Ankara, Turkey.

34. Reuter, M., Xiao, Y., Boin, U., 2004. Recycling and Environmental Issues of Metallurgical Slags and Salt Fluxes, VII International Conference on Molten Slags Fluxes and Salts, The South African Institute of Mining and Metallurgy, pp. 349-356.

35. Krugler, P.E., Freeman, T.J., Wirth, J.E., Wikander, J.P., Estakhri, C.K., Wimsatt, A.J. 2012. Performance Comparison of Various Seal Coat Grades Used in Texas, Citeseer.

36. Karasahin, M., Aktas, B., Gurer, C., 2011. Determining Precoated Aggregate Performance on Chip Seals Using Vialit Test, Transportation Research Board $90^{\text {th }}$ Annual Meeting.

37. Gransberg D.D., James, D.M., 2005. Chip Seal Best Practices Vol. 342: Transportation Research Board.

38. Roberts C., Nicholls, J.C., 2008. Desing Guied for Road Surface Dressing: IHS. 